\title{
INTERNACIONALIZAÇÃO E ESFORÇO INOVATIVO: UMA ANÁLISE COMPARATIVA NAS MULTINACIONAIS DE PAÍSES DESENVOLVIDOS E EM DESENVOLVIMENTO
}

\section{INTERNATIONALIZATION AND INNOVATIVE EFFORT: A COMPARATIVE ANALYSIS IN MULTINATIONALS IN DEVELOPED AND DEVELOPING COUNTRIES}

\author{
Jaluza Maria Lima Silva Borsatto \\ Universidade Federal de Uberlândia - UFU - MG \\ jaluza.silva@ufu.br \\ Simone Vasconcelos Ribeiro Galina \\ Faculdade de Economia, Administração e Contabilidade de Ribeirão Preto - FEA-RP/USP \\ svgalina@usp.br
}

Submissão: $02 / 12 / 2020$

Aprovação: $31 / 05 / 2021$

\section{RESUMO}

Os temas Internacionalização e Inovação vem sendo amplamente debatidos na literatura de negócios. Muitos estudos demonstram haver uma relação de interdependência com a causalidade ocorrendo nos dois sentidos indicando a possibilidade de existir um círculo vicioso. Diante disso, o presente artigo tem por objetivo analisar e comparar a relação entre o grau de internacionalização (GI) e o esforço inovativo por meio da intensidade em P\&D (IP\&D) de empresas multinacionais oriundas de países desenvolvidos (PD) e de países em desenvolvimento (PED). Para a análise realizou-se regressões com dados em painel modelo Pooled a partir de uma amostra com 445 observações de empresas de PD e 473 observações de empresas de PED. De uma forma geral, os resultados indicaram que a formação de aliança para busca de inovação em termos de $\mathrm{P} \& \mathrm{D}$ é negativamente relacionada à distância geográfica entre as empresas, gerando uma importante implicação prática e gerencial no âmbito da literatura sobre internacionalização e inovação. Dessa forma este trabalho contribui jogando luz numa "contra-discussão" dessa temática e ainda aponta a necessidade de pesquisa para repensar a teoria de estratégia internacional, sendo que amplas vias de estudo se abrem para a contribuições para uma 'estratégia regional'.

Palavras-chave: Internacionalização; Esforço Inovativo; Países Desenvolvidos; Países em Desenvolvimento.

\begin{abstract}
The themes of Internationalization and Innovation have been widely debated in the business literature. Many studies show that there is an interdependence relationship with causality occurring in both directions, indicating the possibility of a vicious circle. In view of this, this
\end{abstract}


article aims to analyze and compare the relationship between the degree of internationalization (IG) and the innovative effort through the intensity in R\&D (IP\&D) of multinational companies from developed countries (DP) and developing countries (PED). For the analysis, regressions were performed with data in the Pooled model panel from a sample with 445 observations from PD companies and 473 observations from PED companies. In general, the results indicated that the formation of an alliance to search for innovation in terms of $\mathrm{R} \& \mathrm{D}$ is negatively related to the geographical distance between companies, generating an important practical and managerial implication in the scope of the literature on internationalization and innovation. In this way, this work contributes by throwing light on a "counter-discussion" on this theme and also points out the need for research to rethink the theory of international strategy, with broad avenues of study opening up to contributions to a 'regional strategy'.

Keywords: Internationalization; Innovative Effort; Developed Countries; Emerging Countries.

\section{Introdução}

Com a evolução das relações comerciais entre os países e a consequente abertura dos mercados, dois processos se tornaram indispensáveis para as empresas aumentarem seu nível de competitividade e buscar a melhoria do seu desempenho: a internacionalização e a inovação (KRIZ \& WELCH, 2018). Segundo Chudnovsky e Lopez (2000), a internacionalização é usada como uma alternativa para o crescimento das empresas, permitindo sua exposição a padrões internacionais de produtos, tecnologias e métodos de gestão, gerando importantes retornos para as operações domésticas. Já a inovação em em produto ou processo de negócios novo ou aprimorado, que difere significativamente dos anteriores da empresa e que foi introduzido no mercado ou colocado em uso pela empresa (OECD, 2018), traz vantagem competitiva, ou seja, performance superior para firmas e consequentemente países (Carvalho et al., 2017).

Diante disso, pesquisas sobre a relação entre esses dois processos e seu impacto na competitividade e no desempenho das empresas têm sido feitas por diversos autores. Alguns analisam a inovação como fator motivador da internacionalização (BARRIOS et al, 2003; LOPEZ e GARCÍA, 2005; BECKER e EGGER. 2013; YI et al, 2013; ALTOMONTE et al, 2013), outros o inverso, ou seja, a internacionalização como motivadora da inovação (SALOMON e SHOVER, 2005; VILA e KUSTER, 2007; BRATTI e FELICE, 2012). Há também aqueles que estudam a existência de uma relação complementar entre a inovação e a internacionalização (FILIPESCU, 2011; CHIVA et al, 2013; HALILEM et al, 2014). De uma forma geral, grande parte desses trabalhos encontrou uma relação positiva tanto no aspecto da inovação como causa da internacionalização, quanto no aspecto da internacionalização causando a inovação e na relação de reciprocidade. Entretanto, Bahl et al (2021) encontraram uma associação negativa entre a internacionalização e a probabilidade de inovação de empresas empreendedoras em economias em transição.

Uma característica comum entre essas pesquisas é que a maioria delas estudou a relação entre a internacionalização e a inovação considerando empresas de países desenvolvidos (PD), que possuem maior capacidade financeira para investimentos estrangeiros, e apresentam maior grau de desenvolvimento tecnológico. Assim, uma análise que considere as empresas de países em desenvolvimento (PED), que buscam os mercados externos em função do atual 
contexto de abertura de mercados e de maior exigência dos consumidores, ainda é uma lacuna na literatura (ROSA, 2006; WU, 2007; HSU et al., 2015; RIVIERE, SUDER, 2016).

Este fato é intrigante, pois as empresas multinacionais de países emergentes (EMPEs), neste processo de expansão internacional, podem ter opções estratégicas que não foram vistas em empresas multinacionais de países desenvolvidos (EMPDs) (Ramamurti, 2012). Um exemplo são as condições econômicas do país de origem, que podem influenciar o comportamento e a internacionalização das empresas, oferecendo uma maior chance para o desenvolvimento de teorias mais abrangentes do processo de internacionalização (CUERVO-CAZURRA, 2012).

Segundo Nelson (2006), países emergentes buscam o desenvolvimento tecnológico com atraso, na maior parte das vezes copiando e adaptando soluções exógenas. Porém, já existe um número significativo de empresas desses países que se destacam no mercado global, como resultado de estratégias em que a inovação tecnológica tem papel relevante. O esforço inovador é geralmente recompensado, mas é muito mais difícil em países nos quais a infraestrutura de pesquisa em universidades, institutos e nas próprias empresas é mais modesta.

Dessa forma, acredita-se que uma análise comparativa da relação entre o esforço inovativo e a internacionalização entre países com diferentes economias possa gerar como resultado importantes implicações práticas e gerenciais. Buscando contribuir com a literatura, o presente estudo busca responder à seguinte questão: Qual a relação entre o grau de internacionalização e o esforço inovativo das empresas multinacionais de países desenvolvidos e de países em desenvolvimento?

Assim, o objetivo da pesquisa é analisar e comparar a relação entre o grau de internacionalização (GI) e o esforço inovativo das empresas multinacionais oriundas de países desenvolvidos e de países em desenvolvimento.

Este estudo justifica-se por contemplar a relação entre os temas Internacionalização e Inovação, que necessita ser mais bem explorada na literatura (AHARONI, BROCK, 2010). Ao atender esse objetivo o estudo apresenta uma importante implicação prática e gerencial, pois demonstra que a busca por conhecimento das empresas dos dois grupos de países analisados, PD e PED, se dá majoritariamente em âmbito regional ou local. Logo, é possível inferir que a formação de aliança para busca de inovação em termos de P\&D é negativamente relacionada à distância geográfica entre as empresas, o que corrobora com os achados de Verbeke e Asmussen (2016) e Reuer e Lahiri (2014) realizados em empresas de países desenvolvidos.

\section{Fundamentação Teórica}

O ponto de partida para analisar teoricamente a relação entre a inovação e a internacionalização é o reconhecimento das empresas em adotar esses processos em busca de um melhor nível de competitividade e desempenho. Segundo Altomonte et al. (2013) as empresas mais produtivas apresentam maior intensidade de internacionalização e de inovação, o que impacta positivamente seu desempenho.

A internacionalização é uma alternativa para o crescimento das empresas, permitindo sua exposição a padrões internacionais de produtos, tecnologias e métodos de gestão, gerando importantes retornos para as operações domésticas (CHUDNOVSKY \& LOPEZ, 2000). Seus desafios são grandes, mas existem fatores que motivam este processo, como buscar novas oportunidades por meio de maiores investimentos em inovação; estar entre os líderes do mercado e marcar presença no mercado global; maior economia de escala e aumento da competitividade.

Já a inovação refere-se ao desenvolvimento de novas tecnologias para a elaboração de novos produtos e serviços. Trata-se da forma como as empresas agem frente às mudanças, podendo 
atuar como fonte de satisfação de clientes e funcionários, e melhoria de desempenho operacional e financeiro (TIDD et al, 2008). Entretanto uma versão mais recente do Manual de Oslo pontua o tema inovação com uma abordagem mais ampla considerando quatro dimensões como conhecimento, novidade, implementação e criação de valor. A publicação considera ainda que a inovação é uma mudança significativa em produto ou processo, ou seja, considera-se inovador tudo de diferente que foi disponibilizado para usuários em potencial (produto) ou usado pela organização/empresa (processo) (OECD, 2018).

As empresas que competem no mercado mundial necessitam de diferenciação competitiva, que pode ser possibilitada pela capacidade de realizar inovação (organizacional, de mercado ou tecnológica) de maneira dinâmica e frequente. Por outro lado, ao se internacionalizarem, as empresas podem acessar conhecimento e tecnologia em âmbito mundial para desenvolvimento de soluções inovadoras (CHATENIER et al., 2010).

Além disso, Garrido et al. (2017) afirmam que o desenvolvimento internacional e a capacidade inovativa relacionam-se mutuamente uma vez que atuar no exterior melhora a capacidade inovativa das empresas, e a inovação conduz as empresas ao desenvolvimento de novos produtos, serviços e processos que aumentam a participação delas nos mercados internacionais. Nesta mesma abordagem, Bahl et al. (2021) também verificou que a internacionalização permite que as empresas estendam suas ofertas de produtos a clientes estrangeiros e aumentem seu retorno sobre o investimento, e a inovação resulta no desenvolvimento de novos produtos que os clientes demandam nos mercados interno e externo.

Diante disso, a relação entre inovação e internacionalização é evidente e diversos estudos estão sendo desenvolvidos buscando entendê-la, analisando a temática da seguinte maneira: a inovação como causa da internacionalização; a internacionalização como causa da inovação; e a relação de reciprocidade entre inovação e internacionalização (Quadro 1).

Quadro 1 - Estudos sobre inovação e internacionalização

\begin{tabular}{|c|c|c|c|}
\hline & Inovação como causa da Internacionalização & Região & Metodo/Variáveis \\
\hline $\begin{array}{c}\text { Barrios et al. } \\
(2003)\end{array}$ & $\begin{array}{l}\text { Verificaram que a intensidade de P\&D tem uma influência } \\
\text { importante sobre a decisão de exportar das empresas e do quanto } \\
\text { elas exportam. Além disso, o transbordamento de P\&D exerce um } \\
\text { efeito positivo nas taxas de exportações das empresas, não só para } \\
\text { uso doméstico, mas também para as empresas internacionais. }\end{array}$ & PD & $\begin{array}{l}\text { IP\&D } \\
\text { Tansbordamento de P\&D } \\
\text { Exportações } \\
\text { Tamanho } \\
\text { Idade }\end{array}$ \\
\hline $\begin{array}{c}\text { Lopes e Garcia } \\
(2005)\end{array}$ & $\begin{array}{l}\text { Examinaram a influência da capacidade tecnológica de uma empresa } \\
\text { tanto na sua decisão de exportar como na intensidade de exportação. } \\
\text { Os resultados demonstraram que, as inovações tanto de produtos } \\
\text { como de processos, e as patentes afetam positiva e } \\
\text { significativamente a propensão e a intensidade de exportação de } \\
\text { uma empresa. }\end{array}$ & PD & $\begin{array}{l}\text { Nível de rec. Tecnol. } \\
\text { IP\&D } \\
\text { Inovação Prod. e Proc. } \\
\text { Registro Patentes } \\
\text { Prop. Exportação/vendas } \\
\text { Tamanho, Setor, Prop. } \\
\text { Estrangeira. }\end{array}$ \\
\hline $\begin{array}{l}\text { Frenz et al. } \\
\quad(2005)\end{array}$ & $\begin{array}{l}\text { Testaram a relação entre a multinacionalidade e inovação de } \\
\text { empresas do setor de serviços financeiros. Os resultados mostraram } \\
\text { que a multinacionalidade está positivamente relacionada com as } \\
\text { atividades de inovação, e isso em grande parte devido ao fato de que } \\
\text { as empresas multinacionais operam em países diferentes. }\end{array}$ & PD & $\begin{array}{l}\text { Investimento P\&D } \\
\text { Exportação } \\
\text { Tamanho }\end{array}$ \\
\hline $\begin{array}{c}\text { Vila e Kuster } \\
(2007)\end{array}$ & $\begin{array}{l}\text { Internacionalização não é nem depende de inovação de produto, nem } \\
\text { da inovação de mercado; mas é dependente de inovação da } \\
\text { estratégia. Inovação de processo é dependente de } \\
\text { internacionalização. }\end{array}$ & PD & $\begin{array}{l}\text { Inovação de Produto, Processo, } \\
\text { Mercado e Estratégica } \\
\text { Exportação }\end{array}$ \\
\hline $\begin{array}{l}\text { Dib et al. } \\
(2010)\end{array}$ & $\begin{array}{l}\text { Comprovou empiricamente que uma empresa com maior capacidade } \\
\text { de inovação que seus concorrentes (operacionalizada pelos gastos } \\
\text { com P\&D/Gastos Totais) tende a seguir mais provavelmente um } \\
\text { caminho internacional. }\end{array}$ & PED & Gastos P\&D/Gastos totais \\
\hline Yi et al. (2013) & $\begin{array}{l}\text { Os resultados demonstram que fatores institucionais de localização } \\
\text { específica moderam positivamente os efeitos das capacidades } \\
\text { inovadoras no desempenho das exportações. Consequentemente, a }\end{array}$ & & $\begin{array}{l}\text { Vendas novos prod/Vendas } \\
\text { Totais; Exportação } \\
\text { Propr. Estrangeira }\end{array}$ \\
\hline
\end{tabular}




\begin{tabular}{|c|c|c|c|}
\hline & $\begin{array}{l}\text { relação entre as capacidades inovadoras e desempenho das } \\
\text { exportações não é uniforme, mas depende do contexto institucional } \\
\text { em que a empresa está localizada. }\end{array}$ & PED & $\begin{array}{l}\text { Relação Governo } \\
\text { Grupo empresarial } \\
\text { Comercialização reg. } \\
\text { Tamanho e Idade }\end{array}$ \\
\hline $\begin{array}{l}\text { Altomonte et } \\
\text { al. (2013) }\end{array}$ & $\begin{array}{l}\text { Analisaram firmas majoritariamente inovadoras e e } \\
\text { internacionalizadas e afirmaram que existe uma correlação positiva } \\
\text { entre a internacionalização e a inovação e que há circunstâncias de } \\
\text { análise que evidenciam alguma causalidade da inovação para } \\
\text { internacionalização. }\end{array}$ & PD & $\begin{array}{l}\text { Incentivo P\&D; IP\&D } \\
\text { Intensidade Internac. } \\
\text { País; Setor } \\
\text { Tamanho }\end{array}$ \\
\hline $\begin{array}{l}\text { Becker e Egger } \\
\text { (2013) }\end{array}$ & $\begin{array}{l}\text { Seus resultados mostraram que a inovação de produto é } \\
\text { relativamente mais importante do que a inovação de processos para } \\
\text { aumentar a propensão de exportação de uma empresa, mesmo que } \\
\text { ambos os tipos de inovação exercer uma influência no segundo. }\end{array}$ & PD & $\begin{array}{l}\text { Determinantes da } \text { Inovação } \\
\text { Prod. e Proc. } \\
\text { Exportação }\end{array}$ \\
\hline $\begin{array}{c}\text { Bahl et al } \\
(2021)\end{array}$ & $\begin{array}{l}\text { Verificaram que a internacionalização está associada negativamente } \\
\text { com a probabilidade de inovação e não encontraram nenhuma } \\
\text { evidência de inovação impactando a internacionalização das } \\
\text { empresas. }\end{array}$ & PED & $\begin{array}{l}\text { Variável dummy probabilidade } \\
\text { de inovação; } \\
\text { Variáveis dicotômicas de } \\
\text { Internacionalização. }\end{array}$ \\
\hline \multicolumn{2}{|r|}{ Internacionalização como causa da Inovação } & Região & Metodo/Variáveis \\
\hline $\begin{array}{c}\text { Salomon e } \\
\text { Shaver (2005) }\end{array}$ & $\begin{array}{l}\text { Analisando dados longitudinais de empresas espanholas (1990 a } \\
\text { 1997), descobriram que quando ocorre exportação isso aumenta } \\
\text { duas medidas de inovação das empresas: inovação de produtos } \\
\text { (número de produtos novos ou modificados) e aplicações de } \\
\text { patentes. }\end{array}$ & PD & $\begin{array}{l}\text { Inovação Produtos } \\
\text { Contas de Patentes } \\
\text { Exportação } \\
\text { Tamanho, IP\&D, Intensidade } \\
\text { Publicidade }\end{array}$ \\
\hline $\begin{array}{l}\text { Frenz e Ietto- } \\
\text { Gillies (2007) }\end{array}$ & $\begin{array}{l}\text { Verificaram em seu estudo se a multinacionalidade das empresas } \\
\text { afeta a propensão à inovação, e os resultados apontaram que as } \\
\text { empresas multinacionais são mais propensas a inovar e a } \\
\text { envolverem-se em atividades inovativas. }\end{array}$ & PD & $\begin{array}{l}\text { Resultado da Inovação } \\
\text { Insumos da Inovação } \\
\text { Pedidos de Patente } \\
\text { Grau de Multinacionalidade }\end{array}$ \\
\hline $\begin{array}{l}\text { Bratti e Felice } \\
\text { (2012) }\end{array}$ & $\begin{array}{l}\text { Estudando empresas italianas, verificaram que as exportações têm } \\
\text { uma influência positiva sobre a probabilidade de introdução de } \\
\text { inovações de produto. Este efeito não é devido ao tamanho ou } \\
\text { maiores investimentos em P\&D, mas a heterogeneidade nos gostos e } \\
\text { necessidades do cliente estrangeiro }\end{array}$ & PD & $\begin{array}{l}\text { Var. dicotômica se introduz } \\
\text { inovação/não } \\
\text { Status de Exportação }\end{array}$ \\
\hline $\begin{array}{c}\text { Filippetti et al. } \\
\text { (2013) }\end{array}$ & $\begin{array}{l}\text { Analisaram o impacto da internacionalização na performance da } \\
\text { inovação em } 42 \text { países e confirmou que existe relação entre as } \\
\text { variáveis. }\end{array}$ & $\begin{array}{c}42 \\
\text { países }\end{array}$ & $\begin{array}{l}\mathrm{N}^{\circ} \text { de patentes tríades } \\
\text { Aplicação PCT originárias de } \\
\text { um país. } \\
\text { IDE; Exp e Importação. } \\
\mathrm{N}^{\circ} \text { empresas mãe. }\end{array}$ \\
\hline $\begin{array}{l}\text { Andrade, Bansi } \\
\text { e Galina } \\
\text { (2014) }\end{array}$ & $\begin{array}{l}\text { Analisaram em seu estudo o efeito da internacionalização sobre a } \\
\text { intensidade de inovação, medida através da Pesquisa e } \\
\text { Desenvolvimento (P\&D) e da geração de patentes, em } 219 \text { empresas } \\
\text { multinacionais pertencentes aos BRICS. Os resultados constataram } \\
\text { que quanto maior o grau de internacionalização, maior é o } \\
\text { investimento em inovação, medida pelo investimento em P\&D como } \\
\text { um input deste processo e pelo número de patentes - output do } \\
\text { processo de inovação. }\end{array}$ & PED & $\begin{array}{l}\text { Gastos P\&D } \\
\text { GI = Vendas ext./Vendas totais } \\
\text { Tamanho } \\
\text { Efeitos da indústria } \\
\text { Desempenho }\end{array}$ \\
\hline $\begin{array}{l}\text { Cázares e } \\
\text { Filipescu } \\
(2014)\end{array}$ & $\begin{array}{l}\text { Analisaram se as empresas mais internacionalizadas são mais } \\
\text { eficientes em seu processo de inovação tecnológica e verificaram } \\
\text { que há muito que melhorar em termos de eficiência da inovação } \\
\text { tecnológica, e que empresas mais internacionalizadas fomentam a } \\
\text { melhoria deste processo }\end{array}$ & PD & $\begin{array}{l}\text { Intensidade de Inovação } \\
\text { Tecnológica. } \\
\text { \%Vendas ext./Vendas totais. } \\
\text { Tamanho, Dinamismo do } \\
\text { mercado, } \mathrm{n}^{\circ} \text { de competidores. }\end{array}$ \\
\hline $\begin{array}{l}\text { Boermans e } \\
\text { Roelfsema, } \\
\quad(2015)\end{array}$ & $\begin{array}{l}\text { Demonstraram que a internacionalização aumenta a tendência de } \\
\text { uma empresa de inovar. Mais especificamente, a terceirização está } \\
\text { conectada à inovação de produtos, enquanto a exportação e o IDE } \\
\text { estão associados a gastos de R \& D e patenteamento. }\end{array}$ & PED & $\begin{array}{l}\text { Inovação de Produto } \\
\text { Investimento P\&D } \\
\text { Patentes, Terceirização intern. } \\
\text { Exportação, IDE, Tamanho e } \\
\text { Idade. }\end{array}$ \\
\hline $\begin{array}{l}\text { Bansi et al. } \\
\text { (2021) }\end{array}$ & $\begin{array}{l}\text { Verificaram que na EMNs nos BRICS a internacionalização tem } \\
\text { efeito positivo na inovação. }\end{array}$ & PED & $\begin{array}{l}\text { Intensidade P\&D; Patentes; } \\
\text { Grau de Internacionalização; } \\
\text { Desempenho e Tamanho das } \\
\text { empresas. }\end{array}$ \\
\hline $\begin{array}{l}\text { Lúcio e } \\
\text { Bronnemann } \\
\quad(2021)\end{array}$ & $\begin{array}{l}\text { Demonstraram que os indicadores de insumos (inputs) como de } \\
\text { resultados (outputs) de internacionalização têm influência } \\
\text { significativa nas notas do ranking de inovação e que os PED } \\
\text { encontram maior dificuldade em internacionalizar suas empresas, } \\
\text { prejudicando assim sua capacidade inovativa. }\end{array}$ & PED & $\begin{array}{l}\text { IDE, Negócios Joint Venture, } \\
\text { Importações de alta tecnologia, } \\
\text { Importação de serviços, Gastos } \\
\text { médios P\&D }\end{array}$ \\
\hline
\end{tabular}




\begin{tabular}{|c|c|c|c|}
\hline \multicolumn{2}{|r|}{ Relação recíproca entre Internacionalização e Inovação } & Região & Metodo/Variáveis \\
\hline $\begin{array}{l}\text { Filipescu } \\
(2006)\end{array}$ & $\begin{array}{l}\text { Confirmou em seu estudo que existe uma relação recíproca entre } \\
\text { internacionalização e inovação, e dependendo do modo de entrada } \\
\text { dessas empresas em outros países, a companhia adquire certo tipo de } \\
\text { conhecimento no qual conduz a certo tipo de inovação tecnológica. }\end{array}$ & PD & Estudo de caso \\
\hline $\begin{array}{c}\text { Castro et al. } \\
\text { (2008) }\end{array}$ & $\begin{array}{l}\text { Analisaram empresas brasileiras por meio de estudo de caso } \\
\text { qualitativo, e demonstraram que existe forte relação entre o grau de } \\
\text { internacionalização e a prática de inovação tecnológica e sugeriram } \\
\text { que essa relação pode ser considerada como um determinante para a } \\
\text { competitividade global das empresas analisadas. }\end{array}$ & PED & Múltiplos casos \\
\hline $\begin{array}{l}\text { Filipescu et al. } \\
\text { (2009) }\end{array}$ & $\begin{array}{l}\text { Defendem haver uma relação mútua entre inovação tecnológica e } \\
\text { internacionalização, onde um processo alimenta o outro e vice-versa. } \\
\text { Em seu estudo buscou determinar a relação de interdependência } \\
\text { recíproca entre Inovação e Internacionalização e identificar quais os } \\
\text { fatores que interferem nessa relação. }\end{array}$ & PED & Estudo de caso \\
\hline $\begin{array}{l}\text { Filippetti et al. } \\
\text { (2011) }\end{array}$ & $\begin{array}{l}\text { Analisaram a relação entre o perfil internacional e sua capacidade de } \\
\text { inovação utilizando dados de } 32 \text { países europeus. Os resultados } \\
\text { sugeriram que há uma associação entre inovação e } \\
\text { internacionalização, ou seja, as empresas inovadoras são mais bem- } \\
\text { sucedidas em competir internacionalmente e a exposição a contextos } \\
\text { empresariais e de inovação alternativos leva à inovação. }\end{array}$ & PD & \\
\hline $\begin{array}{l}\text { Golovko e } \\
\text { Valentini } \\
(2011)\end{array}$ & $\begin{array}{l}\text { Analisando empresas espanholas, afirmam que inovação e } \\
\text { exportação reforçam positivamente um ao outro em um 'círculo } \\
\text { virtuoso dinâmico'. Efeito positivo da atividade de inovação na taxa } \\
\text { de crescimento da empresa é maior para empresas que também se } \\
\text { dedicam a exportações e vice-versa }\end{array}$ & PD & $\begin{array}{l}\text { Atividade de Inovação } \\
\text { Exportação } \\
\text { Taxa de crescimento } \\
\text { Tamanho, Capital estrangeiro, } \\
\text { Fusão e Ano. }\end{array}$ \\
\hline $\begin{array}{c}\text { Filipescu, et al. } \\
\text { (2013) }\end{array}$ & $\begin{array}{l}\text { Analisando } 696 \text { empresas espanholas com dados em painel, o artigo } \\
\text { mostra que inovação (investimento em } \mathrm{P} \& \mathrm{D} \text {, inovações em produto } \\
\text { e processo) e exportação possuem relação causal recíproca. }\end{array}$ & PD & $\begin{array}{l}\text { IP\&D } \\
\mathrm{N}^{\circ} \text { Inovações Prod., Proc. } \\
\mathrm{N}^{\circ} \text { mercado estrang. } \\
\text { Volume de exportação } \\
\text { Tamanho, Idade e Intensidade } \\
\text { setores tecnológicos. }\end{array}$ \\
\hline $\begin{array}{c}\text { Chiva et al. } \\
\text { (2013) }\end{array}$ & $\begin{array}{l}\text { Existem dois sistemas complexos: Modelo incrementais complexo } \\
\text { sistema adaptativo (aprendizagem adaptativa, a inovação } \\
\text { incremental e baixa internacionalização) e o modelo generativo } \\
\text { complexo sistema global (aprendizagem produtiva, inovação radical } \\
\text { e internacionalização global) }\end{array}$ & PD & Estudo de caso \\
\hline $\begin{array}{l}\text { Halilem et al. } \\
\quad(2014)\end{array}$ & $\begin{array}{l}\text { Há um círculo virtuoso entre as formas de internacionalização. A } \\
\text { inovação de produtos influencia externamente a internacionalização, } \\
\text { inovação de processo, mas poderia ser prejudicial a ele. }\end{array}$ & PD & $\begin{array}{l}\text { Inovação de Produto } \\
\text { Inovação de Processo } \\
\text { Importação } \\
\text { Exportação } \\
\text { Tamanho e Idade. }\end{array}$ \\
\hline
\end{tabular}

Nota: PD - Países Desenvolvidos; PED - Países em Desenvolvimento

Fonte: elaborado pelos autores

De todos os trabalhos previamente apresentados que relacionam o processo de internacionalização aos aspectos de inovação, grande parte encontrou uma relação positiva tanto no aspecto da inovação como causa da internacionalização, quanto no aspecto da internacionalização causando a inovação e na relação de reciprocidade. Porém, a maioria das pesquisas está focada em empresas originárias de PD, demonstrando uma lacuna para pesquisas em empresas de PED. Assim, nos últimos anos, estudos sobre internacionalização e inovação em países em desenvolvimento tem ganhado destaque no mundo acadêmico porque há diferentes questões relacionadas às empresas provenientes destes países que estão em aberto (RAMAMURTI, 2012; CUERVO-CAZURRA, 2012; AHARONI, BROCK, 2010), sendo a internacionalização da inovação uma delas (RIVIERE, SUDER, 2016; HSU et al., 2015; LÚCIO e BRONNEMANN, 2021; BAHL et al. 2021).

A partir dos estudos que abordam o processo de internacionalização de empresas de países emergentes, Cuervo-Cazurra (2012) buscou contribuir para o desenvolvimento de teorias de Negócios Internacionais ampliando os debates dos "Goldilocks" que possuem três pontos de 
vista, hot, cold e just right. No primeiro campo, hot, os autores argumentam que as EMPEs são um fenômeno novo que se comporta de maneira diferente das EMPDs e, portanto, exige novas teorias e modelos para explicar o seu comportamento (GUILLEN, GARCIA, 2009; LUO, TUNG, 2007; MATHEWS, 2006). No segundo ponto de vista, cold, os autores argumentam que o comportamento das EMPEs pode ser facilmente explicado com as teorias existentes e que não são necessárias novas teorias (DUNNING et al. 2008). Já para os defensores do just right a análise das EMPEs pode ajudar a prolongar a teoria e modelos existentes, devido as condições originais destes países (RAMAMURTI, 2009, 2012; RUGMAN, 2010).

Considerando esses três campos do debate, Cuervo-Cazurra (2012) segue a terceira via e defende que as condições do país de origem influenciam o comportamento e a internacionalização das empresas. Além disso, o autor propõe que estudos de EMNEs ajudam a identificar alguns pressupostos não declarados das teorias existentes e propõe que, em áreas em que o país de origem exerce influência limitada, as previsões das teorias existentes para países desenvolvidos são apropriadas.

Neste contexto, alguns estudos sobre o tema têm sido desenvolvidos de forma a contribuir com a literatura. Awate et al. (2015) compararam a internacionalização de P\&D em multinacionais de PD e PED e descobriram que esses dois processos são diferentes. Enquanto a internacionalização de $\mathrm{P} \& \mathrm{D}$ das EMPDs pode ser explicada em termos de estratégias de exploração e criação de competências, a internacionalização de P\&D das EMPEs está enraizada na estratégia global de recuperação das empresas para aproximar dos líderes das indústrias. Além disso, as capacidades inovadoras das EMPEs se desenvolvem mais devagar e com maior dificuldade do que as das subsidiárias das EMPDs.

Assim, baseado nas conclusões de Cuervo-Cazurra (2012) e considerando que os ambientes locais (países) influenciam tanto inovação quanto internacionalização nas empresas, essa análise se faz necessária uma vez que muitos autores defendem que pesquisas focando as diferenças entre EMPDs e EMPEs são fundamentais para o avanço da literatura de international business (RAMAMURTI, 2012; CUERVO-CAZURA, 2014).

Desta forma, há trabalhos que avaliam as empresas tanto em PD como em PED com foco em um único país ou apenas uma região. Portanto, apesar da existência de estudos sobre o tema, é escassa a literatura que compare EMPEs de EMPEs, e a existência de relação mútua entre internacionalização e inovação das empresas, apesar da divergência entre os resultados dos estudos. Dessa forma, são estabelecidas três hipóteses de pesquisa para que se possa verificar a relação entre o grau de internacionalização e a inovação das empresas multinacionais dos países desenvolvidos e dos países em desenvolvimento.

Hipótese 1: O Grau de Internacionalização influencia positivamente o esforço inovativo das empresas multinacionais dos PD e dos PED.

Hipótese 2: O esforço inovativo influencia positivamente o Grau de Internacionalização das empresas multinacionais dos PD e dos PED.

Hipótese 3: Existe uma relação mútua entre as variáveis esforço inovativo e Grau de Internacionalização das empresas multinacionais dos PD e PED.

\section{Método}

\subsection{Amostra e Coleta de dados}

A população e respectiva amostra referem-se às empresas listadas nos rankings de empresas transnacionais não financeiras divulgados pela UNCTAD no World Investment Report 2014 (UNCTAD, 2014). A amostra foi composta por 445 observações de empresas de PD e 473 observações de empresas de PED no período de 2003 a 2013, separadas por região de origem 
e setor. Das EMPDs, 63\% são originárias da Europa e 25\% da América do Norte, sendo a maioria delas das indústrias de base e de bens de consumo (65\%). Já as EMPEs $56 \%$ têm origem na Ásia Oriental e estão distribuídas principalmente entre a indústria de base (22\%), indústria de bens de consumo (19\%) e serviços (18\%), conforme demonstrado na Figura 01.

Figura 01 -Descrição da amostra das empresas por país e por setor

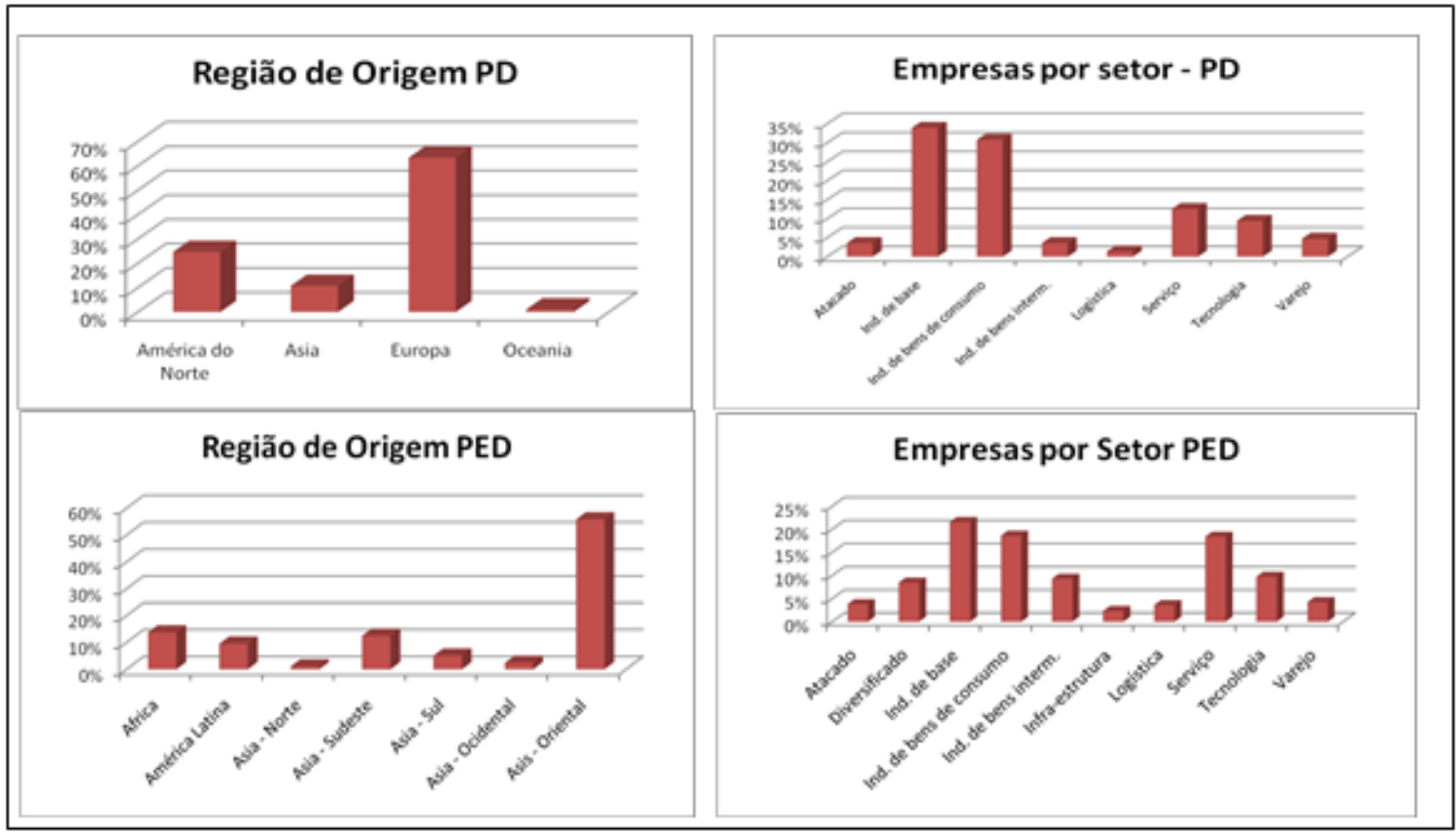

Fonte: Elaboração própria

Para a classificação dos países, foi utilizada a divisão feita pela UNCTAD que separa os países por regiões geográficas. Já para a classificação dos setores, foi utilizada uma combinação entre os setores das empresas dos rankings da UNCTAD e os setores para as mesmas empresas, encontrados no site da Bloomberg, empresa global líder em informações financeiras e de negócios.

Os dados financeiros foram obtidos na base Data Stream, que pertence a Thomson Reuters, e dispõe de dados históricos de demonstrativos financeiros de todas as empresas listadas em bolsa de valores ao redor do mundo. Nessa base de dados foram coletadas as seguintes informações: retorno sobre os ativos (ROA), receita líquida, ativo circulante e passivo circulante, gastos com P\&D e número total de empregados no período de 2003 a 2013. Já os valores do Grau de Internacionalização (GI) das empresas em estudo foram coletados na World Investment Reports da UNCTAD 2014, que dispõem de rankings das empresas mais internacionalizadas de PD e PED.

\subsection{Variáveis em estudo}

A investigação dos dados nesta pesquisa ocorre em três etapas. Primeiro, será analisado se o GI influencia positivamente o esforço inovativo das EMNs dos PD e dos PED. As medidas de inovação geralmente são classificadas em inputs (intensidade $\mathrm{P} \& \mathrm{D}$, qualificação de pessoal em P\&D), capacidades (cultura, liderança, conhecimento, estratégia) e outputs (produção de patentes) (CARVALHO et al. 2017). O presente estudo definiu como variável dependente o esforço inovativo das empresas medido pela intensidade de P\&D (inputs), cujo cálculo se dá pela razão entre os gastos anuais em $P \& D$ sobre as vendas totais. A escolha desta variável se deu pelo fato da intensidade de P\&D ser o indicador mais usado para medir o esforço das empresas em pesquisa e desenvolvimento, além de ser um indicador internacionalmente 
utilizado para comparar setores e países tomando como referência o nível tecnológico desses agentes (FURTADO; QUEIROZ, 2007).

Como variável independente, nesse primeiro modelo, definiu-se o grau de internacionalização, utilizando o Transnationality Index (TNI) ou índice de transnacionalização proposto pela UNCTAD, cujo cálculo se dá pela média aritmética entre três fatores: vendas externas/vendas totais; número de funcionários externos/número de funcionários totais; e valor dos ativos externos/ativos totais. A mensuração da internacionalização é controversa e vem sendo feita por meio de diferentes indicadores (ANNAVARJULA; BELDONA, 2000), mas há uma percepção de que um índice composto tende a ser mais robusto como métrica (SULLIVAN, 1994; WAGNER, RUIGROK, 2004), que é o caso do uso do índice de transnacionalidade da UNCTAD (IETTO-GILLIES, 1998; ANDRADE E GALINA, 2013).

Na segunda etapa da análise, a variável dependente passa a ser o Grau de Internacionalização e a variável independente o esforço inovativo medido pela intensidade de P\&D. Em ambos os processos, de modo a atingir um melhor ajustamento do modelo, foram estabelecidas algumas variáveis de controle, sendo elas: Tamanho da empresa (TAM) medido pelo número de funcionários da empresa; vendas líquidas medida pelo total das receitas líquidas das empresas; o desempenho medido pelo Retorno sobre os Ativos (ROA); a folga organizacional (FO), também chamada de liquidez corrente medida pela razão entre o ativo circulante e o passivo circulante.

A variável tamanho foi uma das variáveis mais analisadas na literatura sobre a relação entre internacionalização e inovação, uma vez que empresas maiores possuem mais recursos disponíveis tanto para investir em inovação como para entrar em mercados internacionais.

Além das variáveis de controle quantitativas, foram inseridas no modelo duas variáveis dummy, região de origem e setor. Segundo Yi et al. (2013) a relação entre as capacidades inovadoras e o desempenho exportador depende do contexto institucional que a empresa está localizada. Desta forma buscou-se verificar nestas variáveis, se a região de origem e o setor de atuação das empresas influenciam a relação entre o GI e o esforço inovativo das empresas.

Para representar o setor de atuação das empresas, nos PD, formulou-se um conjunto de oito variáveis dummy (Atacado; Indústria de Base; Indústria de bens de consumo; Indústria de bens intermediários; Logística; Serviço; Tecnologia; e Varejo); e nos PED formulou-se um conjunto de dez variáveis dummy (Atacado; Diversificado; Indústria de Base; Indústria de bens de consumo; Indústria de bens intermediários; Infraestrutura; Logística; Serviço; Tecnologia; e Varejo). Para representar a variável regiões de origem, em PD foram formuladas quatro variáveis dummy (América do Norte; Ásia; Europa; e Oceania). Já para os PED, foi formulado um conjunto de sete variáveis dummy (África, América Latina, Ásia Norte; Ásia -Sudeste; Ásia - Sul; Ásia - Ocidental; Ásia - Oriental).

O Quadro 3 apresenta a descrição das variáveis utilizadas para análise, bem como os autores que já utilizaram as mesmas métricas em suas investigações empíricas.

Quadro 3: Descrição das variáveis do estudo

\begin{tabular}{|c|c|c|c|c|}
\hline Variáveis & Sigla & Definição & Forma de mensuração & Autores \\
\hline Internacionalização & GI & $\begin{array}{c}\text { Grau de } \\
\text { Internacionalização } \\
\text { (UNCTAD) }\end{array}$ & $\begin{array}{c}\text { Média aritmética de (ativos no } \\
\text { exterior/ativo), (vendas no } \\
\text { exterior/vendas) e (funcionários no } \\
\text { exterior/funcionários) }\end{array}$ & (12); (15) \\
\hline Inovação & IP\&D & $\begin{array}{c}\text { Esforço Inovativo } \\
\text { (Intensidade em } \\
\text { P\&D) }\end{array}$ & Investimento em P\&D/Vendas Totais & (14); (15) \\
\hline
\end{tabular}




\begin{tabular}{|c|c|c|c|c|}
\hline \multirow{4}{*}{ Controle } & TAM & Tamanho & Logaritmo do número de funcionários & $\begin{array}{c}(6) ;(7) ; \\
(8) ;(10) ; \\
(13) ;(15)\end{array}$ \\
\cline { 2 - 5 } & FO & $\begin{array}{c}\text { Folga } \\
\text { Organizacional }\end{array}$ & Ativo Circulante/Passivo Circulante & - \\
\cline { 2 - 5 } & ROA & $\begin{array}{c}\text { Retorno sobre o } \\
\text { Ativo }\end{array}$ & Lucro Líquido / Ativo Total & $\begin{array}{c}(1) ;(2) ; \\
(3) ;(4) ; \\
(5) ;(15)\end{array}$ \\
\cline { 2 - 5 } & & Vendas Líquidas & & $\begin{array}{c}(1) ;(2) ; \\
(11) ;(13)\end{array}$ \\
\cline { 2 - 5 } & & Dummy Setor & & $(9) ;(13)$ \\
\hline
\end{tabular}

Nota: (1) Hoskisson (1987); (2) Grant et al. (1988); (3) Haar (1989); (4) Kim et al. (1989); (5) Habib e Victor (1991); (6) Capar; Kotabe (2003); (7) Contractor et al. (2003); (8) Frenz et al. (2005); (9) Li (2005); (10) Chang (2007); (11) Gaur; Kumar (2009); (12) Andrade e Galina (2013); (13) Altomonte et al. (2013); (14) Andrade et al. (2014); (15) Bansi et al. (2021).

Fonte: Elaborado pelo autor

\subsection{Técnicas Estatísticas}

As três hipóteses desta pesquisa foram testadas por meio de regressões lineares com dados em painel, o que se justifica em função da estrutura dos dados utilizada apresentar características de cross-section (i) relacionadas com as características das organizações ao longo de uma série temporal (t). Além disso, para oferecer um resultado empírico mais robusto, assim como foi feito por Filipescu et al. (2013), realizou-se o teste de causalidade de Granger (Granger, 1969) para avaliar a natureza da relação causal entre as variáveis esforço inovativo e internacionalização, e verificar uma possível endogeneidade relacionada às variáveis. Os resultados estatísticos foram obtidos por meio do Stata SE.

\section{Apresentação e Discussão dos Resultados}

\subsection{Análise descritiva}

As Tabelas 1 e 2 apresentam as estatísticas descritivas e as correlações das variáveis envolvidas no estudo. As EMNs de PD apresentaram em média um maior GI e uma maior intensidade em P\&D que as EMNs dos PED, demonstrando que são empresas mais inovadoras e mais internacionalizadas. Além disso, as EMNs dos PD apresentaram, em média, um maior volume de vendas líquidas, porém a rentabilidade média medida pelo ROA foi inferior à rentabilidade média das EMNs dos PED.

Observou-se também que as variáveis independentes não são altamente correlacionadas entre si, não apresentando problemas de multicolinariedade. Segundo Hair et al. (1998), para o atendimento aos pressupostos da Regressão Múltipla, os resultados não revelam qualquer problema de forte multicolinearidade, quando as variáveis independentes não são altamente correlacionadas entre si.

Tabela 1. Média, Desvio-padrão e correlações entre variáveis das EMNs dos PD

\begin{tabular}{|c|c|c|c|c|c|c|c|c|c|}
\hline Variáveis & Obs. & Média & $\begin{array}{c}\text { Desvio } \\
\text { Padrão }\end{array}$ & GI & ROA & $\begin{array}{c}\text { Vendas } \\
\text { Líquidas }\end{array}$ & IP\&D & FO & TAM \\
\hline GI (\%) & 445 & 60.671 & 16.252 & 1.000 & & & & & \\
\hline ROA & 445 & 7.3252 & 5.3259 & -0.105 & 1.000 & & & & \\
\hline Vendas líq. & 445 & $7.64 \mathrm{e}+$ & $7.50 \mathrm{e}+$ & -0.172 & 0.168 & 1.000 & & & \\
\hline IP\&D (\%) & 445 & .02610 & .04202 & -0.058 & 0.078 & 0.189 & 1.000 & & \\
\hline
\end{tabular}




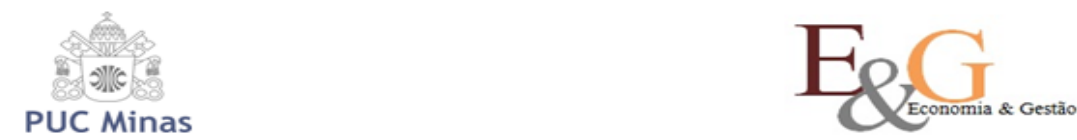

PUC Minas

\begin{tabular}{c|ccccccccc} 
FO & 445 & 1.1696 & .42079 & 0.063 & 0.139 & -0.096 & 0.119 & 1.000 & \\
TAM & 445 & 11.566 & .90636 & -0.139 & 0.067 & 0.161 & 0.180 & -0.220 & 1.000
\end{tabular}

Tabela 2. Média, Desvio-padrão e correlações entre variáveis das EMNs dos PED

\begin{tabular}{c|ccccccccc}
\hline Variáveis & Obs. & Média & $\begin{array}{c}\text { Desvio } \\
\text { Padrão }\end{array}$ & GI & ROA & $\begin{array}{c}\text { Vendas } \\
\text { Líquidas }\end{array}$ & IP\&D & FO & TAM \\
\hline GI & 473 & 54.111 & 24.766 & 1.000 & & & & & \\
ROA & 473 & 8.7092 & 7.7403 & 0.179 & 1.000 & & & \\
Vendas líq. & 473 & $1.78 \mathrm{e}+$ & $3.58 \mathrm{e}+$ & -0.208 & 0.057 & 1.000 & & & \\
IP\&D & 473 & .00661 & .01261 & 0.065 & 0.221 & -0.092 & 1.000 & & \\
FO & 473 & 1.533 & .99167 & 0.169 & 0.286 & -0.103 & 0.519 & 1.000 & 1.000 \\
TAM & 473 & 9.964 & 1.4036 & -0.189 & -0.158 & 0.438 & 0.099 & -0.225 &
\end{tabular}

\subsection{Análise das Relações entre Inovação e Internacionalização}

Além da análise de correlações entre as variáveis independentes, para verificação de problemas de multicolinariedade, foram feitas as estatísticas Tolerance e Variance Inflation Factor (VIF) para ambas as amostras, e não foram detectados, por meio desses testes, problemas de multicolinariedade, pois os valores de VIF médio para as EMNs dos PD e dos PED foram 3,62 e 2,46, respectivamente. Além disso, os dados atenderam a outros pressupostos da regressão, como ausência de autocorrelação serial (Teste Durbin-Watson 1,81 PD e 2,248 PED), dentro da faixa de ausência de autocorrelação.

Para a análise de regressão foram realizados testes para três abordagens distintas, Pooled, modelos de efeitos fixos, e modelos de efeitos aleatórios. Os resultados apontaram o modelo Pooled como o mais adequado, e para testar as hipóteses da pesquisa aplicou-se o modelo de regressão linear cujos dados gerais foram $\mathrm{R}^{2}$ : 0.477 e $\mathrm{R}^{2}$ ajustado: 0.453 para PED, e $\mathrm{R}^{2}$ : $0.547, \mathrm{R}^{2}$ ajustado: 0.531 para $\mathrm{PD}$ ao nível de significância $\mathrm{p}<0,05$, conforme demonstrado na Tabela 3 .

Tabela 3. Resultados da regressão linear modelos Pooled

\begin{tabular}{|c|c|c|c|c|c|}
\hline \multicolumn{3}{|c|}{ Países em Desenvolvimento } & \multicolumn{3}{|c|}{ Países Desenvolvidos } \\
\hline & IP\&D (1) & GI (2) & & IP\&D (1) & GI (2) \\
\hline $\mathrm{ROA}$ & $0.0002 * *$ & -0.0172 & $\mathrm{ROA}$ & 0.0006 & $0.4695 * * *$ \\
\hline VL & $0.0000^{*}$ & $-0.0000 * * *$ & VL & -0.0000 & 0.0000 \\
\hline FO & $0.0021 * * *$ & -1.3944 & FO & $0.0491 * * *$ & $4.9161 * * *$ \\
\hline TAM & $0.0016 * * *$ & -0.7780 & TAM & 0.0019 & -1.4710 \\
\hline GI & $-0.0001 * * *$ & & GI & $-0.0003 * * *$ & \\
\hline IP\&D & & $\begin{array}{c}97.6444 \\
(108.1537)\end{array}$ & IP\&D & & -14.7674 \\
\hline Região de Origem & & & Região de Origem & & \\
\hline Am. Latina & -0.0008 & -2.3283 & Ásia & -0.0052 & 3.2401 \\
\hline Ásia - Norte & -0.0006 & 0.0000 & Europa & 0.0015 & $11.5258 * * *$ \\
\hline Ásia - Sudeste & -0.0006 & $17.6910 * * *$ & Oceania & -0.0092 & $8.1584 * *$ \\
\hline Ásia - Sul & 0.0036 & 5.6924 & & & \\
\hline Ásia - Ocident. & 0.0006 & 0.0000 & & & \\
\hline Ásia - Oriental & $0.0055 * * *$ & -2.5493 & & & \\
\hline Setor & & & Setor & & \\
\hline Diversificado & -0.0002 & $-32.4470 * * *$ & Ind. Base & 0.0044 & $11.1884 * * *$ \\
\hline Ind. Base & $0.0055 * * *$ & $-11.2828 * * *$ & $\begin{array}{l}\text { Ind. Bens } \\
\text { Consumo }\end{array}$ & $0.0502 * * *$ & $15.1274 * * *$ \\
\hline $\begin{array}{l}\text { Ind. Bens } \\
\text { Consumo }\end{array}$ & -0.0003 & $-37.1269 * * *$ & $\begin{array}{l}\text { Ind. Bens } \\
\text { Intermediários }\end{array}$ & $0.0295 * * *$ & $15.6514 * * *$ \\
\hline $\begin{array}{l}\text { Ind. Bens } \\
\text { Intermediários }\end{array}$ & $0.0106 * * *$ & -4.3471 & Logística & $0.0245 * *$ & 0.0000 \\
\hline Infra-estrutura & -0.0013 & $-55.0863 * * *$ & Serviço & $0.0284 * * *$ & $13.2067 * *$ \\
\hline
\end{tabular}




\begin{tabular}{lcc|lcc} 
Logística & 0.0002 & 0.0000 & Tecnologia & $0.0563 * * *$ & $18.5001 * * *$ \\
Serviço & -0.0015 & $-26.9226 * * *$ & Varejo & $0.0150 *$ & 0.0000 \\
Tecnologia & $0.0215 * * *$ & $-21.7519 * * *$ & & & \\
Varejo & 0.0039 & 0.1980 & & & \\
Constante & $-0.0184 * * *$ & $81.4799 * * *$ & Constante & $-0.0676 * * *$ & $46.8502 * * *$ \\
& & & & & \\
\hline N (empresas) & $\mathbf{4 7 3}$ & $\mathbf{2 1 1}$ & N (empresas) & $\mathbf{4 4 5}$ & $\mathbf{0 5 6}$ \\
$\mathbf{R}^{2}$ & $\mathbf{0 . 4 7 7}$ & $\mathbf{0 . 4 6 2}$ & $\mathbf{R}^{2}$ & $\mathbf{0 . 5 4 7}$ & $\mathbf{0 . 1 9 2}$ \\
$\mathbf{R}^{2}$ ajustado & $\mathbf{0 . 4 5 3}$ & $\mathbf{0 . 4 1 3}$ & $\mathbf{R}^{2}$ ajustado & $\mathbf{0 . 5 3 1}$ & $\mathbf{0 . 1 6 1}$ \\
Rmse & $\mathbf{0 . 0 0 9 3}$ & $\mathbf{1 7 . 3 6 0 4}$ & Rmse & $\mathbf{0 . 0 2 8 8}$ & $\mathbf{1 3 . 7 0 9 4}$ \\
\hline
\end{tabular}

Nota. Variável dependente (1) Intensidade de Pesquisa e Desenvolvimento; (2) Grau de Internacionalização. Significativo ao nível de $10 \%(*), 5 \%(* *)$ e $1 \%(* * *)$. Legenda das variáveis: ROA - Retorno sobre o Ativo; VL - Vendas Líquidas; FO - Folga Operacional; TAM - Tamanho; GI - Grau de Internacionalização. A América do Norte e o setor Atacado foram utilizados como bases na regressão para os Países Desenvolvidos. A África e o setor Atacado foram utilizados como bases na regressão para os Países em Desenvolvimento.

\subsubsection{Internacionalização influenciando na inovação}

Na primeira etapa do estudo o intuito foi analisar se o GI influencia positivamente o esforço inovativo por meio da intensidade de P\&D das EMNs dos PD e PED. O GI apresentou uma relação negativa com a intensidade de P\&D para EMNs tanto em PD (-0.0003) quanto nos PED (-0.0001) ao nível de significância de $\mathrm{p}<0,01$, indicando que quanto mais internacionalizada for a empresa, menor será seu esforço inovativo por meio da intensidade de P\&D, rejeitando a Hipótese 1 deste estudo.

Isso nos leva à reflexão de que, embora a literatura tenha apontado vantagens das firmas que utilizam suas inserções internacionais para inovar, há indícios de que é necessário repensar se realmente a busca pelo conhecimento para inovação acontece em esfera global. Estudos recentes têm mostrado o contrário, Verbeke e Asmussen (2016) indicam que a busca por conhecimento se dá majoritariamente em âmbito regional ou local. Reuer e Lahiri (2014), numa pesquisa sobre colaboração para $\mathrm{P} \& \mathrm{D}$ na indústria de semicondutores, apontam que a probabilidade de formação de aliança para inovação é negativamente relacionada à distância geográfica.

Uma explicação para esse fato é apontada por Capaldo e Petruzzelli (2015), que concluem que, para aproveitar ao máximo a busca de conhecimento, as empresas que realizam P\&D internacionalmente devem procurar parcerias com quem possui conhecimento geograficamente distante, mas organizacionalmente próximo. Na verdade, a questão da proximidade entre parceiros - seja geográfica, cultural, tecnológica, institucional ou outras (Knoben, Oerlemans, 2006) - tem sido focada por estudos recentes, isso porque entendimento sobre distância ainda é uma lacuna na literatura de negócios internacionais e, portanto, uma área importante de estudos (HUTZSCHENREUTER, et al., 2016; ZAHEER et al., 2012). Portanto os resultados deste trabalho contribuem indicando a necessidade de maior entendimento da relação entre internacionalização e inovação.

Em relação às variáveis de controle presentes no modelo, em EMNs dos PED, a Folga Operacional e o Tamanho da empresa apresentaram uma relação positiva com a intensidade de $\mathrm{P} \& \mathrm{D}(\mathrm{p}<0.01)$, e o Desempenho medido pelo ROA também apresentou uma relação positiva com a intensidade de $\mathrm{P} \& \mathrm{D}(\mathrm{p}<0.05)$. Isso demonstra que nos $\mathrm{PED}$, empresas de maior porte que possuem uma Folga Operacional maior e um melhor desempenho financeiro medido pelo ROA são mais engajadas nas atividades de $\mathrm{P} \& \mathrm{D}$.

Nas EMNs dos PD, somente a Folga Organizacional apresentou uma relação positiva com a intensidade de $\mathrm{P} \& \mathrm{D}(\mathrm{p}<0.01)$, demonstrando que estas empresas apresentam um volume maior de vendas e uma maior folga organizacional (também chamada de liquidez corrente), com isso uma maior disponibilidade de recursos para em investir em P\&D. 
Os resultados referentes à relação positiva entre FO e inovação obtidos para ambos PED e PD corroboram com análises anteriores dessa temática, já que quando há pouca folga, espera-se que a inovação seja prejudicada porque a experimentação é desencorajada, enquanto uma folga excessiva significava que não há gestão eficiente de projetos (Nohria, Gulati, 1996). Dessa forma, este trabalho mostra a importância da folga organizacional nos projetos inovadores, assim como o de Richtnér et al. (2014), que concluem que mudanças na folga impacta na criação do conhecimento.

Dentre as variáveis Região de Origem e Setor, os resultados indicaram que, nas EMNs dos PED, somente a região da Ásia Oriental apresentou significância estatística $(\mathrm{p}<0.01)$ na relação com a intensidade de $\mathrm{P} \& \mathrm{D}$. O que pode ser justificado por fazer parte desta região os PED China, Coréia do Sul e Taiwan, cujos crescimentos se destacam entre as economias emergentes do mundo. Já nas EMNs dos PD nenhuma região interfere na intensidade de investimentos em $\mathrm{P} \& \mathrm{D}$, ou seja, por se tratar de países com mesmo nível de desenvolvimento, a região de origem não é fator significativo para o maior ou menor engajamento da empresa em atividade de $\mathrm{P} \& \mathrm{D}$.

$\mathrm{Na}$ variável Setor, verificou-se que os setores da Indústria de Base, Indústria de Bens Intermediários e o Setor de Tecnologia possuem uma relação positiva com o engajamento das EMNs dos PED nas atividades de inovação ( $\mathrm{p}<0.01)$. Já nos PD os setores de Bens de Consumo, Bens Intermediários, Serviços e Tecnologia apresentaram relação positiva com a intensidade em $P \& D(p<0.01)$, e o setor de logística a um nível de significância $p<0.05$. Esta divergência da influência dos setores dos PED e PD pode ser atribuída ao fato de que em economias emergentes, há um investimento maior em infraestrutura e produção de insumos para atender os setores de Bens Intermediários e Bens de Consumo, e em economias desenvolvidas, há um maior investimento em inovação em setores que irão atender o cliente final com produtos e serviços de maior valor agregado.

\subsubsection{Inovação influenciando a internacionalização}

$\mathrm{Na}$ segunda etapa desta pesquisa, analisou-se se o esforço inovativo influencia positivamente o Grau de Internacionalização das EMNs dos PD e PED. Os resultados indicaram que não há relação entre a intensidade de $\mathrm{P} \& \mathrm{D}$ e o GI nem das EMNs dos PD nem dos PED, não corroborando com os resultados dos estudos de Barrios et al (2003), Becker e Egger (2013), Dib et al. (2010) e Altomonte et al (2013), que encontraram uma relação positiva entre inovação e internacionalização, rejeitando também a Hipótese 2 deste estudo.

No que diz respeito às variáveis de controle, nas EMNs dos PED, apesar de apresentarem uma rentabilidade média e uma folga operacional maior que as EMNs dos PD, estas variáveis não afetam o GI, ou seja, esse melhor desempenho financeiro não está fazendo com que estas empresas invistam mais os mercados internacionais. Esse resultado é contrário ao trazido por trabalhos anteriores, que mostram que FO modera positivamente a relação entre GI e performance em multinacionais dos PED, como dos BRICs (Andrade et al., 2015) ou de Taiwan (Lin et al., 2011).

Por outro lado, nas EMNs dos PD, as variáveis ROA e FO apresentaram influência positiva no GI ( $\mathrm{p}<0.05)$, demonstrando que quanto maior o desempenho e a folga organizacional das empresas, maior a disposição das empresas em internacionalizar-se. Além disso, esses resultados demonstram que estas empresas estão destinando seus recursos para investimentos internacionais.

Quanto às variáveis dummy, nas EMNs dos PED, a Região do Sudeste da Ásia foi a única a apresentar influência positiva no GI ( $\mathrm{p}<0.01)$, indicando que empresas desta região tendem a ser mais internacionalizadas, o que pode ser explicado pelo fato de apesar de serem regiões em desenvolvimento, nela estão localizados países como Cingapura e Indonésia, que possuem 
economias exportadoras com elevada atividade industrial de EMNs de outros países. Em PD, as regiões da Europa e Oceania apresentaram relação positiva com o GI $(\mathrm{p}<0.01$ e p<0.05). Em relação à variável setor, nos $\mathrm{PED}$, todos os setores, exceto o de Bens Intermediários, apresentaram uma relação negativa com o GI a um nível de significância $\mathrm{p}<0.01$, demonstrando que os setores considerados neste estudo influenciam de forma inversa o nível de internacionalização das empresas. Nos PD, contrário ao que acontece nos PED, todos os setores, exceto Logística e Varejo, apresentaram uma relação positiva com o GI das EMNs $(\mathrm{p}<0.01)$.

\subsubsection{Relação de Reciprocidade entre Internacionalização e Inovação}

Na terceira etapa do estudo, buscou-se verificar a existência de uma relação mútua entre as variáveis esforço inovativo e internacionalização. Assim como feito no estudo de Filipescu et al (2013), realizou-se o teste de causalidade de Granger, onde os resultados estão demonstrados na Tabela 4.

Tabela 4. Teste de Causalidade de Granger das variáveis - IP\&D e GI

\begin{tabular}{ccc|ccc}
\hline Equation & $\begin{array}{c}\text { PED } \\
\text { Excluded }\end{array}$ & Prob>chi2 & Equation & $\begin{array}{c}\text { PD } \\
\text { Excluded }\end{array}$ & Prob>chi2 \\
\hline IP\&D & GI & 0.016 & IP\&D & GI & 0.756 \\
IP\&D & ROA & 0.567 & IP\&D & ROA & $0.036^{* *}$ \\
IP\&D & VL & & IP\&D & VL & \\
IP\&D & FO & 0.338 & IP\&D & FO & $0.021^{* *}$ \\
IP\&D & TAM & 0.132 & IP\&D & TAM & 0.172 \\
\hline GI & IP\&D & 0.371 & GI & IP\&D & 0.100 \\
GI & ROA & 0.734 & GI & ROA & 0.317 \\
GI & VL & 0.365 & GI & VL & 0.840 \\
GI & FO & 0.269 & GI & FO & 0.055 \\
GI & TAM & 0.151 & GI & TAM & 0.104 \\
\hline
\end{tabular}

Nota: ** e *** significativo ao nível de $5 \%$ e $1 \%$ respectivamente. Legenda das variáveis: ROA -

Retorno sobre o Ativo; VL - Vendas Líquidas; FO - Folga Operacional; TAM - Tamanho; GI - Grau de

Internacionalização; IP\&D - Intensidade de P\&D; PED - Países em Desenvolvimento; PD - Países

Desenvolvidos. Resultado do Teste: $\mathrm{H}_{0}$ - não há causalidade entre as variáveis do modelo.

A partir dos resultados, observa-se que tanto para os PED como para os $\mathrm{PD}$, não foi possível rejeitar a hipótese nula de ausência de causalidade, pois em todos os casos o GI não causou IP\&D, e a IP\&D não causou o GI, ou seja, não houve relação de bicausalidade de Granger entre as variáveis, não corroborando com os resultados de Filipescu et al. (2013), que encontrou uma relação causal recíproca entre inovação de processo e inovação de produto com as exportações em empresas Espanholas. Desta forma, os resultados não confirmam a Hipótese 3 deste estudo, da existência de uma relação mútua entre as variáveis Intensidade de P\&D e GI das EMNs dos PD e PED.

A partir destas análises e considerando algumas divergências e convergências nos resultados das EMNs dos PD e PED, este estudo corrobora com o debate dos "Goldilocks", seguindo a terceira via (JUST RIGHT) defendida por Cuervo-Cazurra (2012), que argumenta que as condições de origem influenciam o comportamento e a internacionalização das empresas, e a análise das EMNs dos PED pode ajudar a prolongar a teoria e modelos existentes, devido às condições originais destes países. Os resultados deste estudo demonstraram que as EMNs dos PED cuja região de origem são países com maior nível de desenvolvimento econômico são mais internacionalizadas, assim como as EMNs dos PD, ajudando a confirmar o argumento de Cuervo-Cazurra (2012). 


\section{Considerações Finais}

Este estudo analisou a relação entre o GI e o esforço inovativo por meio da IP\&D das EMNs dos PD e dos PED. Para atingir esse objetivo, primeiramente foi verificado se o GI influencia positivamente o esforço inovativo, por meio da IP\&D dessas empresas. Os resultados demonstraram que isso não aconteceu, ou seja, o GI apresentou uma relação negativa com a intensidade de P\&D para EMNs, tanto em PD quanto nos PED. Num segundo momento foi analisado se o esforço inovativo influencia positivamente o GI das empresas em estudo. Os resultados apontaram que não há relação entre a intensidade de P\&D e o GI, nem das EMNs dos PD nem dos PED. Por último analisou-se a existência de uma relação de interdependência entre o esforço inovativo e o GI. Tanto para os PED, como para os PD, os resultados demonstraram que não houve uma relação de bi-causalidade entre as variáveis em estudo.

Os resultados deste trabalho divergem do que a literatura "mainstream" vem apresentando sobre o tema. Quando abordamos a internacionalização como causa da inovação, autores como Frenz e Ietto-Gillies (2007), Andrade et al (2014) e Bansi et al. (2021) evidenciaram que empresas mais internacionalizadas são mais propensas a inovar e possuem maior investimento em inovação, o que não foi comprovado neste estudo, e que pode ser explicado pela forma diferente de mensurar as variáveis de internacionalização e inovação. A maioria dos estudos pesquisados utilizaram como medida de internacionalização variáveis que medem o desempenho das exportações, e diversas medidas de inovação como patentes, inovação de produtos, processos e outros, diferente do presente estudo que usou somente da IP\&D que reflete apenas um aspecto parcial da dimensão tecnológica das empresas.

Quando se abordou a inovação como causa da internacionalização, autores como Barrios et al (2003), Dib et al (2010) e Altomonte et al (2013) demonstraram que empresas com maior intensidade de inovação tendem a ser mais internacionalizadas, o que também não foi confirmado neste trabalho. E por fim na análise de relação mútua entre as variáveis, autores como Filipescu et al. (2013) e Golovko e Valentini de (2011) encontraram uma relação causal recíproca entre inovação e internacionalização, porém utilizando também variáreis distintas as utilizadas nesta pesquisa.

Como os resultados apresentaram divergências significativas em relação à literatura dominante na área, este trabalho contribui jogando luz numa "contra-discussão" dessa temática, conforme vem sendo abordado mais recentemente (Verbeke e Asmussen, 2016; Reuer e Lahiri, 2014). Verbeke e Asmussen (2016) ainda apontam a necessidade de pesquisa para repensar a teoria de estratégia internacional, sendo que amplas vias de estudo se abrem para a contribuições para uma 'estratégia regional'.

Assim, este trabalho contribui com a literatura mostrando a necessidade de futuros estudos, uma vez que há fatores ainda não explicados, que interferem na relação entre inovação e internacionalização. Isso demonstra a necessidade de estudos adicionais sobre o tema, utilizando outras variáveis para mensurar tanto a inovação como a internacionalização, além de estudos comparativos entre empresas de PD e PED. Além dessa contribuição, este estudo empírico comparativo com empresas multinacionais de PD e de PED de diversos setores busca de ampliar o conhecimento acerca das relações entre Inovação e Internacionalização em contextos distintos de países, atendendo uma necessidade de avanço da literatura nesse aspecto. 


\section{REFERÊNCIAS}

AHARONI, Y.; BROCK, D. International Business Research: Looking back and looking forward. Journal of International Management. Vol. 16, n. 1, p. 5-15, 2010.

ALTOMONTE, C.; AQUILANTE, T.; BÉKÉS, G.; OTTAVIANO, G. I. Internationalization and innovation of firms: Evidence and policy. Economic Policy, V. 28, n. 76, p. 663-700, 2013.

ANNAVARJULA, Madan; BELDONA, Sam. Multinationality-performance relationship: A review and reconceptualization. The International Journal of Organizational Analysis, v. 8, n. 1, p. 48-67, 2000.

ANDRADE, A. M. F.; GALINA, S. V. R. Efeitos da Internacionalização sobre o Desempenho de Multinacionais de Economias em Desenvolvimento. RAC, v. 17, n. 2, art. 6, pp. 239-262, Mar./Abr. 2013.

ANDRADE, A. M. F.; BANSI, A. C.; GALINA, S. V. R. Efeitos da Internacionalização sobre a Intensidade de Inovação nas empresas dos BRICS. XXXVIII Enanpad. Setembro, 2014.

BAHL, Mona; LAHIRI, Somnath; MUKHERJEE, Debmalya. Managing internationalization and innovation tradeoffs in entrepreneurial firms: Evidence from transition economies. Journal of World Business, v. 56, n. 1, p. 101150, 2021.

BANSI, Ana Claudia; DE ANDRADE, Alisson Maxwell Ferreira; GALINA, Simone Vasconcelos Ribeiro. A relação entre rnternacionalização e inovação nas multinacionais de países emergentes. Revista Eletrônica de Negócios Internacionais: Internext, v. 16, n. 1, p. 110-126, 2021.

BARRIOS, S.; GÖRG, H.; STROBL, E. Explaining firms’ export behaviour: R\&D, spillovers and the destination market*. Oxford Bulletin of Economics and Statistics. Vol. 4, n. 65, p. 475-496, 2003.

BECKER, S. O.; EGGER, P. H. Endogenous product versus process innovation and a firm's propensity to export. Empirical Economics, V. 44, n. 1, p. 329-354, 2013.

BOERMANS, M. A.; ROELFSEMA, H. The effects of internationalization on innovation: Firm-level evidence for transition economies. Open Economies Review, V. 26, n. 2, p. 333 $350,2015$.

BRATTI, M.; FELICE, G. Are exporters more likely to introduce product innovations? The World Economy, V. 35, n. 11, p. 1559-1598, 2012.

CAPALDO, Antonio; MESSENI PETRUZZELLI, Antonio. Origins of knowledge and innovation in R\&D alliances: a contingency approach. Technology Analysis \& Strategic Management, v. 27, n. 4, p. 461-483, 2015.

CARVALHO, G. D. G. et al. Innovativeness measures: a bibliometric review and a classification proposal. International Journal of Innovation Science, v. 9, n. 1, p. 81-101, 2017.

CASTRO, A. M. P.; SOUZA, C.; PISCOPO, M. R. Explorando a internacionalização das empresas brasileiras e sua relação com a Inovação Tecnológica. ReA - UFSM. Revista de Administração da Universidade Federal de Santa Maria. V.1, p.366-382, 2008. 
CAZÁRES, C. C.; FILIPESCU, D. A. Measuring the Effects of Internationalization on Technological Innovation Efficiency. In: DRUID Society Conference 2014, CBS, Copenhagen, June 16-18, 2014.

CHATENIER, D.; VERSTEGEN, J.; BIEMANS, H., Mulder, M. e Omta, O. Identification of competencies for professional in open innovation teams. R\&D Management, v. 40, n. 3, p. 271-280. 2010

CHIVA G. R., GHAURI, P., ALEGRE VIDAL, J. Organizational learning, innovation and inrternationalization: A complex system model. 2013.

CHUDNOVSKY, D. LOPEZ, A. As multinacionais latino-americanas: Evolução e Perspectivas de Empresas da Argentina, Brasil, Chile e México, Revista Brasileira de Comércio Exterior, Rio de Janeiro: Funcex, 2000.

CUERVO-CAZURRA, Alvaro. Extending theory by analyzing developing country multinational companies: Solving the Goldilocks debate. Global Strategy Journal, v. 2, n. 3, p. 153-167, 2012.

CONTRACTOR, F. J.; KUNDU, S. K.; HSU, C. C. A three-stage theory of expansion of international expansion: the link between multinationality and performance in the service sector. Journal of International Business Studies, v. 34, p. 5-18, 2003.

DIB, L. A.; ROCHA, A.; SILVA, J. F. The internationalization process of Brazilian software firms and the born global phenomenon: Examining firm, network, and entrepreneur variables. Journal of international entrepreneurship, v. 8, n. 3, p. 233-253, 2010.

FILIPESCU, D. A. Innovation and internationalization - a focus on exporting firms. Advances in International Marketing, v.20, p. 125-154, 2006.

FILIPESCU, D.A.; RIALP. A.; RIALP, J. Internationalization and technological innovation: Empirical evidence on their mutual relationship. In R.R. Sinkovics and P.N. Ghauri (Ed.), New Challenges to International Marketing (Advances in International Marketing, Volume 20): p. 125-154. Emerald Group Publishing Limited, 2009.

FILIPESCU, D. Internationalisation and technological innovation: Empirical evidence on their relation Universitat Autónoma de Barcelona, 2011.

FILIPESCU, Diana A. et al. Technological innovation and exports: Unpacking their reciprocal causality. Journal of International Marketing, v. 21, n. 1, p. 23-38, 2013.

FILIPPETTI, A.; FRENZ, M.; IETTO-GILLIES, G. Are innovation and internationalization related? An analysis of European countries'. Industry and Innovation. V. 18, n. 5, 2011.

FILIPPETTI, A.; FRENZ, M.; IETTO-GILIES, G. The Role of Internationalization as a Determinant of Innovation Performance. An Analysis of 42 Countries. CIMR Research Working Paper Series. N.10, 2013.

FRENZ, M.; GIRARDONE, C.; IETTO-GILLIES, G. Multinationality Matters in Innovation: The Case of the UK Financial Services. Industry and Innovation. V. 12, n. 1, p. 65-92, Mar 2005.

FRENZ, M.; IETTO-GILLIES, G. Does multionationality affect the propensity to innovate? An analysis of the trhird UK Community Innovation Survey. International Review of Applies Economics, v. 21, n.1, p99-117, 2007. 
GARRIDO, Ivan Lapuente et al. Mantendo-se inovadoras: O papel do desempenho passado, da capacidade absortiva e da internacionalização. BBR. Brazilian Business Review, v. 14, n. 6, p. 559-574, 2017.

GOLOVKO, E.; VALENTINI, G.; Exploring the Complementarity Between Innovation and Export for SMEs Growth. Journal of International Business Studies, V.42 n.3, p.362-80, 2011.

GRANGER, C. W.J. Investigating Causal Relations by Econometric Models and CrossSpectral Methods, Econometrica, v.37, n.3, p.424-38, 1969.

HAIR, J. F.; ANDERSON, R. E.; TATHAM, R. L.; BLACK, W. C. Multivariate data analysis. New Jersey: Upper Saddle River: Prentice Hall, 1998.

HALILEM, N.; AMARA, N.; LANDRY, R. Exploring the relationships between innovation and internationalization of small and medium-sized enterprises: A non recursive structural equation model. Canadian Journal of Administrative Sciences / Revue Canadienne Des Sciences De l'Administration. V. 31, n. 1, p. 18-34, 2014.

HSU, C. W., LIEN, Y. C., \& CHEN, H. R\&D internationalization and innovation performance. International Business Review, 24(2), 187-195, 2015.

IETTO-GILLIES, Grazia. Different conceptual frameworks for the assessment of the degree of internationalization: an empirical analysis of various indices for the top 100 transnational corporations. Transnational corporations, v. 7, p. 17-40, 1998.

KRIZ, Alexandra; WELCH, Catherine. Innovation and internationalisation processes of firms with new-to-the-world technologies. Journal of International Business Studies, v. 49, n. 4, p. 496-522, 2018.

LÓPEZ RODRÍGUEZ, J.; GARCÍA RODRÍGUEZ, R. M. Technology and export behaviour: A resource-based view approach. International Business Review. V. 14, n. 5, p. 539-557, 2005 .

NOHRIA, N., R. GULATI. Is slack good or bad for innovation? Academy of Management Journal v. 39, n.5, pp. 1245-1264, 1996.

OECD. Oslo Manual - Guidelines for Collecting, Reporting and Using Data on Innovation, The Measurement of Scientific, Technological and Innovation Activities. Paris: OECD Publishing, v. 2018, p. 85-102, 2018.

RAMAMURTI R. 2012. What is really different about emerging market multinationals? Global Strategy Journal, v.2, n.1, p. 41-47, 2012.

REUER, Jeffrey J.; LAHIRI, Nandini. Searching for alliance partners: Effects of geographic distance on the formation of R\&D collaborations. Organization Science, v. 25, n. 1, p. 283 298, 2014.

RICHTNÉR, A., ÅHLSTRÖM, P., GOFFIN, K. Squeezing R\&D: A Study of Organizational Slack and Knowledge Creation in NPD, Using the Seci Model. Journal of Product Innovation Management. V. 31, n. 6, pp. 1268-1290, 2014.

RIVIERE, M.; SUDER, G.. Perspectives on strategic internationalization: Developing capabilities for renewal. International Business Review, v. 25, n. 4, p. 847-858, 2016. 
ROSA, P.R.da. Internacionalização da Empresa Marcopolo S.A.: Um estudo de caso. Dissertação de Mestrado. Programa de Pós - Graduação em Administração da Universidade Federal do Rio Grande do Sul. 2006.

SALOMON, R. M.; SHAVER, J. M. Learning by exporting: New insights from examining firm innovation. Journal of Economics\& Management Strategy. V. 14, n. 2, p. 431- 460, 2005.

SULLIVAN, Daniel. Measuring the degree of internationalization of a firm. Journal of international business studies, v. 25, n. 2, p. 325-342, 1994.

UNCTAD. World Investment Report 2014 (WIR 2014): Investing in the Sustainable Development Goals: An Action Plan. UNCTAD, 2014.

VERBEKE, A.; ASMUSSEN, C. G. Global, Local, or Regional? The Locus of MNE Strategies. Journal of Management Studies. 2016

VILA, N.; KUSTER, I. The importance of innovation in international textile firms. European Journal of Marketing, V. 41, n. 1/2, p. 17-36, 2007.

WAGNER, H.; RUIGROK, W. Internationalization and performance: a meta-analytic review and future research directions. In: Academy of International Business annual meeting, Stockholm, Sweden. 2004.

YI, J.; WANG, C.; KAFOUROS, M. The effects of innovative capabilities on exporting: Do institutional forces matter? International Business Review. V. 22, n. 2, p. 392-406, 2013.

ZAHEER, S., SCHOMAKER, M. S.; NACHUM, L. Distance without direction: Restoring credibility to a much-loved construct. Journal of International Business Studies, 43(1), 18-27, 2012. 